\title{
Regulação da contabilidade: teorias e análise da convergência dos padrões contábeis brasileiros aos IFRS*
}

\author{
Ricardo Lopes Cardoso** \\ Enrique Saravia*** \\ Fernando Guilherme Tenório**** \\ Marcelo Adriano Silva*****
}

SumÁrio: 1. Introdução; 2. Regulação do quê? 3. Teorias da regulação; 4. A Lei noo 11.638/07 e a MP no 449/08; 5. Considerações finais.

Summary: 1. Introduction; 2. Regulating what? 3. Regulation theories; 4. Act n. 11.638/07 and Provisionnal Act n. 449/05. 5. Final remarks.

\footnotetext{
* Artigo recebido em dez. 2008 e aceito em maio 2009. Uma versão preliminar deste artigo foi apresentada no $18^{\circ}$ Congresso Brasileiro de Contabilidade realizado na cidade de Gramado - RS, no dia 28 de agosto de 2008 , e recebeu o 1o prêmio de melhor artigo científico apresentado no evento. Uma versão ainda mais simplificada foi apresentada e debatida no $3^{\text {rd }}$ Audit and Accounting Convergence 2008 Annual Conference realizado na cidade de Cluj-Napoca - Romênia, no dia 31 de outubro de 2008. A presente versão contempla as sugestões dos revisores ad hoc e dos congressistas desses dois eventos, a quem somos gratos, e atualiza a análise da regulação de acordo com a Medida Provisória no 449/08. Agradecemos o apoio institucional da Ebape/FGV.

** Doutor em ciências contábeis pela Universidade de São Paulo (FEA/USP). Professor adjunto da Escola Brasileira de Administração Pública e de Empresas da Fundação Getulio Vargas (Ebape/FGV) e da Universidade do Estado do Rio de Janeiro (Uerj). Endereço: Praia de Botafogo, 190, sala 501 - Botafogo - CEP 22250-090, Rio de Janeiro, RJ, Brasil. E-mail: ricardo.lopes. cardoso@fgv.br.

*** Doutor em direito pela Université de Paris 1, Panthéon-Sorbonne. Professor titular da Escola Brasileira de Administração Pública e de Empresas da Fundação Getulio Vargas (Ebape/FGV). Endereço: Praia de Botafogo, 190, sala 520 - Botafogo - CEP 22250-090, Rio de Janeiro, RJ, Brasil.E-mail:enrique.saravia@fgv.br.

**** Doutor em engenharia da produção pela Universidade Federal do Rio de Janeiro (Coppe/ UFRJ). Professor titular da Escola Brasileira de Administração Pública e de Empresas da Fundação Getulio Vargas (Ebape/FGV). Endereço: Praia de Botafogo, 190, sala 507 - Botafogo - CEP 22250-090, Rio de Janeiro, RJ, Brasil. E-mail: fernando.tenorio@fgv.br.

****** Mestre em administração pela Escola Brasileira de Administração Pública e de Empresas da Fundação Getulio Vargas (Ebape/FGV). Professor convidado do FGV Management. Endereço: Estrada Francisco da Cruz Nunes, 777, alameda 1, casa 16 - Piratininga - CEP 24350-150, Niterói, Rio de Janeiro, RJ, Brasil. E-mail: madrianosil@uol.com.br.
} 
Palavras-chave: regulação da contabilidade; regulação contábil; teoria do interesse público; teoria da captura; teoria da competição dos grupos de interesse; teoria tridimensional; abordagem de Habermas e Laughlin; teoria da contabilidade.

KEY WORDS: regulation of accounting; accounting regulation; public interest theory; capture theory; interest group theory; tridimensional theory; Habermas and Laughlin approach; accounting theory.

O processo de convergência das práticas nacionais de contabilidade aos padrões internacionais implica profundas alterações na regulação da contabilidade. É natural que os contabilistas estejam preocupados em se adaptar aos "novos" padrões buscando adotá-los, e auditar sua adoção nas respectivas empresas/clientes. Entretanto, tão importante quanto adotar e auditar a adoção dos International Financial Reporting Standards (IFRS) nas demonstrações contábeis das empresas brasileiras é compreender o movimento de alteração das normas contábeis em âmbito nacional. Por outro lado, pouco se tem discutido sobre os impactos dessas novas regulamentações. Este artigo analisa, numa perspectiva interdisciplinar, o processo de alteração da regulação da contabilidade à luz de cinco teorias da regulação. Embora as teorias sejam concorrentes, observou-se que elas podem ser utilizadas de forma complementar entre si na compreensão das alterações promovidas pela Lei ํㅜ 11.638/07 e pela Medida Provisória $\mathrm{n}^{\circ}$ 449/08 na Lei $\mathrm{n}^{\mathrm{0}} 6.404 / 76$. Considerou-se que as teorias realiana e habermasiana são as que melhor contribuem para a democratização da contabilidade, uma vez que consideram os valores sociais na elaboração e posterior interpretação da regulação.

\section{Accounting regulation: theories and analysis of the Brazilian accounting standards convergence to IFRS}

The convergence process of local accounting standards into international standards requires significant changes in accounting regulation. Accountants and auditors are working hard to understand and familiarize themselves with these "new" standards in order to adopt and audit them at their firms and/or clients. However, adopting and auditing the adoption of International Financial Reporting Standards (IFRS) are just as important as understanding the changes in local accounting regulation. Also, the impact of the new regulation has been little discussed. This theory-based article examines the Brazilian IFRS convergence experience through an interdisciplinary perspective. Although all five theories of regulation examined are concurrent, they can provide complementary explanations for the IFRS convergence phenomenon. Reale's and Habermas's approaches were considered those that better contribute to accounting democracy, since they adopt social values in the regulation design and interpretation.

\section{Introdução}

É inegável que as recentes alterações dos padrões contábeis brasileiros em convergência aos internacionais consistem no tema contábil mais relevante desta década. A começar pelo Comunicado no 14.259/06 do Banco Central do Brasil 
(Bacen), e pela edição das Deliberações nos 488/05 e 489/05 e da Instrução no 457/07 da Comissão de Valores Mobiliários (CVM). Processo que ganhou maior ímpeto com a edição da Lei no 11.638/07 e, posteriormente, em ordem cronológica com a divulgação do Comunicado ao Mercado emitido pela CVM em 14 de janeiro de 2008, a adoção do Framework for the Preparation and Presentation of Financial Statements (elaborado pelo International Accounting Standards Board - Iasb, traduzido pelo Comitê de Pronunciamentos Contábeis - CPC e aprovado pela CVM), a consequente revogação da Deliberação CVM no 29/86 pela Deliberação CVM no 539/08, além da edição da Medida Provisória (MP) no 449/08 e da publicação de mais de 13 pronunciamentos contábeis pelo CPC. Provas dessa relevância são os incontáveis seminários e painéis realizados nestes dois anos, destinados ao debate da Lei no 11.638/07 e da adoção dos International Financial Reporting Standards (IFRS) no Brasil. Sem falar no movimento editorial para se atualizar a literatura de contabilidade societária, ${ }^{1}$ além dos inúmeros artigos publicados em jornais e periódicos especializados, como Valor Econômico, Gazeta Mercantil, Carta Capital e Conjuntura Econômica.

Não obstante toda essa atenção à nova regulamentação, pouca ênfase tem sido dispensada ao processo de regulação. Os livros de teoria da contabilidade não discutem as teorias da regulação, muito menos como tais teorias se aplicam à regulação da contabilidade; no máximo apresentam, nos capítulos iniciais, comentários sobre o movimento regulatório (normalmente, estadunidense), numa abordagem histórica. ${ }^{2}$

Este artigo apresenta, numa perspectiva interdisciplinar, algumas teorias da regulação e como elas ajudam a compreender o fenômeno da regulação

\footnotetext{
${ }^{1}$ Exemplos desse movimento no mercado editorial são: o lançamento do suplemento à 7 ạ edição do Manual de contabilidade, de Sérgio de Iudícibus, Eliseu Martins e Ernesto R. Gelbcke; o lançamento do livro Mudanças contábeis na Lei Societária: Lei no 11.638, de 28-12-2007, de Hugo Rocha Braga e Marcelo Cavalcanti de Almeida; o lançamento da 2 a edição do livro Contabilidade geral: introdução à contabilidade societária, de Natan Szuster, Ricardo Lopes Cardoso, Fortunée, Fernanda e Flávia Rechtman Szuster; e o lançamento do livro Manual de normas internacionais de contabilidade: IFRS versus normas brasileiras, de Ernst \& Young e Fipecafi.

${ }^{2}$ Aqui cabem comentários sobre duas recentes alterações na regulação da contabilidade nos Estados Unidos ainda não cobertas nas seções de "perspectivas históricas" dos livros brasileiros de teoria da contabilidade. Desde março de 2007, a Securities and Exchange Commission (SEC) estuda a possibilidade de permitir que empresas estrangeiras cujos títulos (American depositary receipts - ADR) são negociados nas bolsas estadunidenses publiquem suas demonstrações contábeis em consonância aos IFRS sem necessidade de convertê-los para os padrões contábeis daquele país (Usgaap), o que foi aprovado no final de 2008. Em agosto de 2008, a SEC propôs para debate a minuta de uma norma segundo a qual aceitará, a partir de 2014, que empresas estadunidenses cujas ações são negociadas nos EUA publiquem suas demonstrações contábeis em IFRS.
} 
da contabilidade e a consequente regulação contábil, tomando como exemplo a recém-edição da Lei oํ 11.638/07 e da MP no 449/08. Portanto, está organizado da seguinte forma: na próxima seção é apresentado o conceito de contabilidade adotado neste artigo; na seção 3 são apresentados os aspectos gerais das cinco teorias da regulação selecionadas para tentar compreender as alterações da Lei no 6.404/76 (Lei das Sociedades por Ações — LSA); a seção 4 é dedicada à apresentação e interpretação das principais alterações promovidas pela Lei no 11.638/07 e pela MP no 449/08 na LSA, à luz das cinco teorias da regulação. Finalmente, a última seção apresenta as considerações finais e propostas para futuras pesquisas.

\section{Regulação do quê?}

Este artigo aborda especificamente a regulação da contabilidade, portanto, é importante deixar claro o que se entende por contabilidade.

McCowen (1946) apresenta a contabilidade como uma arte. Pode-se até concordar com essa definição, mas ela não ajuda em nada a discussão sobre regulação, posto que, sob tal perspectiva, estar-se-ia analisando a regulação de uma arte, o que poderia ser confundido com censura, alternativa que não é muito promissora.

Mautz (1963) e Sterling (1975) apresentam a contabilidade como uma ciência social. Não se discorda dessa definição, mas ela também não é útil ao estudo da regulação, pois, "regular uma ciência" demanda, talvez, conhecimento supracientífico.

Anthony e Reece (1989:3) apresentam a contabilidade como uma ferramenta (ou sistema) que gera informação sobre o patrimônio e o desempenho das entidades. Essa definição é bastante útil para se ensinar contabilidade a não contadores, entretanto, pouco ajuda ao estudo da regulação. Afinal, a regulação de uma ferramenta poderia ser uma atividade de engenheiros ou torneiros mecânicos da mesma forma que a regulação de sistemas de informação poderia ser atividade para técnicos em sistemas de informação, o que, certamente, não é o foco deste artigo.

Portanto, para se analisar a regulação da contabilidade, é mais adequado entender a contabilidade como um conjunto de mecanismos dedicado à redução da assimetria informacional, ao delineamento de incentivos e à estruturação e sinalização de mecanismos de avaliação de desempenho ou, de forma mais ampla, como uma instituição social (Ordelheide, 2004). Como instituição social, é importante conhecer os atores sociais que interagem e 
compartilham as crenças e os valores que constituem a contabilidade; nesse sentido, Beaver (1998:13) apresenta os componentes do ambiente das demonstrações contábeis.

\section{Quadro 1}

\section{Componentes do ambiente das demonstrações contábeis}

\begin{tabular}{|c|c|c|}
\hline \multirow[t]{3}{*}{1 - Investidores } & A. & Diversificados versus não diversificados \\
\hline & B. & Ativos versus passivos \\
\hline & C. & Profissionais versus não profissionais \\
\hline \multirow{5}{*}{$\begin{array}{l}2 \text { - Intermediários da } \\
\text { informação }\end{array}$} & A. & Analistas financeiros \\
\hline & B. & Agências de rating de dívidas \\
\hline & C. & Agências de rating de ações \\
\hline & D. & Consultores de investimentos \\
\hline & E. & Corretoras de valores \\
\hline \multirow[t]{3}{*}{3 - Reguladores } & A. & Fasb (lasb, CPC) \\
\hline & B. & SEC (Iosco, CVM) \\
\hline & C. & Congresso \\
\hline \multirow[t]{2}{*}{4 - Gestores } & A. & Empresas de grande porte versus pequeno porte \\
\hline & B. & Companhias abertas versus empresas fechadas \\
\hline \multirow[t]{2}{*}{5 - Auditores } & A. & Empresas internacionais versus empresas locais \\
\hline & B. & Registrados na SEC [CVM] versus não registrados na SEC [CVM] \\
\hline
\end{tabular}

Fonte: Adaptado de Beaver (1998:13).

\section{Teorias da regulação}

Teóricos do direito e da economia, individualmente ou em conjunto, como os adeptos da law \& economics, têm estudado a regulação há décadas. Diversas teorias surgiram para explicar a regulação e predizer quando e quais mercados provavelmente seriam regulados ou desregulamentados, bem como para mostrar como ela aparece, se desenvolve e declina. Essas teorias podem ser meramente descritivas dos fenômenos regulatórios, podem ser prescritivas de como deve ser organizado o processo de regulação, ou podem ser uma combinação das duas perspectivas. Entre essas diversas teorias, cinco merecem destaque, pois podem ajudar a compreender a regulação da contabilidade.

Segundo a taxonomia proposta por Viscusi, Vernon e Harrington Jr. (2000:313-330), a evolução das teorias da regulação pode ser analisada em 
três estágios: a análise normativa como a teoria positiva (aqui denominada teoria do interesse público); a teoria da captura; e a teoria econômica da regulação (aqui denominada teoria da competição entre os grupos de interesse). Além dessas, são apresentadas a teoria tridimensional do direito e a teoria de Habermas.

\section{Teoria do interesse público}

A teoria do interesse público segue a visão clássica da regulação que teria como propósito zelar pelo interesse público. Portanto, sempre que este estiver na iminência de ser atingido, o Estado (órgão regulador) deve agir, por exemplo, para evitar que determinada empresa com concentração do poder de mercado (um monopolista) prejudique os consumidores. Segundo essa teoria, a regulação é justificada, principalmente, para os casos que envolvem monopólios naturais e externalidades negativas. Assim, os atores da regulação funcionam como agentes do interesse público. O propósito da regulação é atingir certos resultados desejados pela comunidade e que o mercado não teria condições de facilitar.

Beaver (1998:164) explica a teoria do interesse público: "este ponto de vista assume implicitamente tanto que os incentivos do regulador são alinhados ao interesse público quanto que o interesse público é bem definido". Baldwin e Cave (1999) acrescentam que é muito difícil identificar o interesse público, já que a regulação geralmente acontece no meio de um conflito entre diversas concepções sobre o interesse público e essa teoria não dá conta desse confronto. King (2006:55-56) sugere que as normas societárias e contábeis expedidas pelo congresso estadunidense em 1933 e 1934 objetivaram zelar pelo interesse público a fim de se recuperar a credibilidade nas bolsas de valores e de se evitar que novas crises ocorressem. Da mesma forma, King (2006:187188) sugere que a Sarbanes-Oxley Act também objetivou zelar pelo interesse público, que fora afetado negativamente, no início deste século, por fraudes praticadas por grandes corporações.

Verrecchia (2004) apresenta as externalidades da divulgação ao público, o peso morto da busca privada por informações, o oportunismo do gestor (e demais usuários internos da firma) e os custos de agência como argumentos em defesa da regulação da evidenciação das informações contábeis, como se tais características ambientais fossem "falhas de mercado".

Laughlin (2007:277-278) utiliza ironicamente o termo "interesse público" como justificativa do governo conservador de Margaret Thatcher, durante 
a Guerra Fria, para banir a divulgação da demonstração do valor adicionado, no Reino Unido, em 1979, simplesmente quatro anos após sua divulgação ter se tornado obrigatória por meio do The Corporate Report, instituído pelo governo do Partido Trabalhista.

\section{Teoria da captura}

A teoria da captura surgiu como contraponto à teoria do interesse público, uma vez que diversas evidências empíricas apresentavam provas de que a regulação fora exercida em prol da empresa regulada e, consequentemente, em detrimento da sociedade.

Beaver (1998:164) explica a teoria da captura: "o principal beneficiário da regulação não é o público (ou investidores, no caso da Lei das Sociedades por Ações), mas aqueles sendo regulados". Segundo Stigler e Friedland (1962), a regulação do serviço de energia elétrica (um monopólio natural) garantiu lucros anormais para as concessionárias do serviço público em detrimento dos consumidores. Cohen e Stigler citados por Beaver (1998:165) apresentam os principais beneficiários da legislação societária (securities acts) como os membros da comunidade de investidores profissionais em vez dos investidores individuais de uma forma mais ampla. Viscusi, Vernon e Harrington Jr. (2000:317-318) afirmam que, segundo a teoria da captura, ou a regulação é oferecida como resposta à demanda da indústria por regulação de forma que "os legisladores são capturados pela indústria", ou a agência reguladora se torna controlada pela indústria com o passar do tempo, isto é, "os reguladores são capturados pela indústria".

\section{Teoria da competição entre os grupos de interesse}

Pelo fato das duas teorias estudadas se posicionarem nos extremos e se basearem exclusivamente em evidências empíricas, foram duramente criticadas, até que emergiu a teoria da competição entre os grupos de interesse, segundo a qual, o legislador e o regulador estão preocupados em se perpetuarem no poder. Portanto, a regulação é desenhada para atender às necessidades do grupo de interesse que exercer maior pressão relativa sobre o regulador e o legislador. Os formuladores da teoria veem regulação como o produto da relação de diferentes grupos entre si e destes com o Estado. Para eles, a regulação não está imbuída de espírito público, mas sim de competição pelo poder (Balwin 
e Cave, 1999). Diversos são os autores dessa corrente: Stigler (1971), Posner (1971), Peltzman (1976) e Becker (1983) são exemplos.

A teoria da competição entre os grupos de interesse pode ser visualmente explicada pela física mecânica, teoria dos vetores. A regulação pode ser representada por um pêndulo e as pressões exercidas pelos grupos de interesse correspondem aos vetores de força. Caso as forças sejam exercidas em mesma intensidade e em sentidos opostos, o pêndulo permanece parado (a regulação é mantida no status quo). Por outro lado, o grupo que conseguir exercer pressão relativa maior que os demais grupos de interesse provavelmente obterá a regulação conforme suas demandas. Segundo essa teoria, as pressões são exercidas das mais diversas formas, inclusive financiamentos de campanha eleitoral.

Alguns autores dessa corrente tentam conciliar o interesse público com as perspectivas dos grupos de interesse. É o caso de Bernstein (1955), que sublinha o papel dos reguladores que devem implementar as missões que os legisladores negociaram entre grupos de interesse (consumidores, empresas e outras partes afetadas) - missões que firmam compromissos, mas que são vistas pelos participantes como formas de proteger o interesse público.

McLeay, Ordelheide e Young (2004) adotam como referencial teórico a teoria da competição entre os grupos de interesse para analisar os impactos de três diferentes grupos de interesse (lobby) - contadores que trabalham nas indústrias (elaboradores de demonstrações contábeis), auditores e acadêmicos - na adaptação à legislação alemã da quarta diretiva europeia sobre legislação societária (comercial). Os resultados empíricos apresentam que os acadêmicos alemães participaram mais ativamente no processo de convergência aos padrões internacionais do que os auditores, entretanto, suas propostas obtiveram a menor taxa de aceitação; quanto aos elaboradores das demonstrações contábeis, foram os mais ativos e suas propostas foram majoritariamente aceitas. Adicionalmente, McLeay, Ordelheide e Young (2004) evidenciam que o alinhamento entre pelo menos dois grupos de interesse aumenta significativamente a probabilidade da proposta ser aceita pelo legislador.

As três teorias já apresentadas têm em comum o fato de seguirem a linha de law \& economics, mas essa não é a única abordagem de se analisar a regulação. Há teorias que seguem uma vertente filosófica e sociológica, como a teoria tridimensional do direito, de Miguel Reale, (aqui denominada teoria tridimensional) e a abordagem desenvolvida por Habermas e interpretada por Laughlin. Ressalte-se que essas duas últimas teorias são alinhadas ao ponto de vista de Ordelheide (2004: 273) que afirma:

a contabilidade, como qualquer instituição social, só existe porque pensamos sobre e a concebemos (...) a contabilidade existe porque acreditamos que ela 
existe. Evoco essa noção para demonstrar que o conteúdo que concebemos para a contabilidade é determinado pelas funções que associamos a ela. A contabilidade é um instrumento, um meio para um fim, e tais fins é que lhe imbuem significado (...) a contabilidade se torna uma instituição social quando as partes envolvidas compartilham uma visão comum sobre suas funções, e a contabilidade só pode exercer as funções que forem compartilhadas por seus usuários (...) essas funções têm uma característica normativa implícita. Disso tudo, segue que valores, desejos e utilidades constituem a contabilidade.

\section{Teoria tridimensional}

A teoria desenvolvida por Reale ${ }^{3}(1963,1977,1994,1995,1996,2005)$ procurava entender a elaboração de normas jurídicas, daí porque é conhecida por teoria tridimensional do direito. Segundo Reale, a regulação é uma construção social que decorre da dinâmica dialética entre o fato, o valor e a norma.

Resumidamente, pode-se dizer que a norma (N) é produzida por um órgão dotado de poder normativo $(\mathrm{P})$ que interpreta os fatos (F) à luz dos valores (V1, V2, V3) compartilhados pela sociedade (intenções de valor), conforme o que seja entendido por "interesse público" (direções normativas). A figura 1 ajuda a entender esse processo.

\section{Processo normativo segundo Reale}

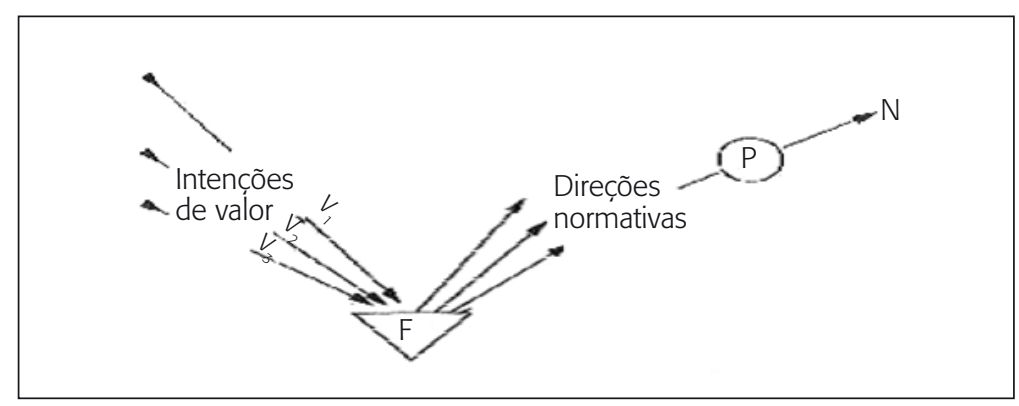

Fonte: Reale, 2005:123.

\footnotetext{
${ }^{3}$ Miguel Reale nasceu em São Bento do Sapucaí (SP), em 6 de novembro de 1910, exerceu a advocacia desde 1934, foi professor de direito, escreveu diversas obras sobre filosofia e filosofia do direito, supervisionou a comissão que elaborou o novo Código Civil, foi condecorado com o título doutor honoris causa por diversas universidades brasileiras e estrangeiras, faleceu em 14 de abril de 2006.
} 
Pohlmann e Alves (2004:239) propuseram que a teoria realiana poderia ser utilizada para se compreender a regulação da contabilidade, mas foi Silva (2007) quem efetivamente adaptou a teoria tridimensional do direito à regulação da contabilidade.

Silva (2007:148-149) conclui que:

Os três elementos considerados essenciais para o estudo da teoria tridimensional do direito, o fato, a norma e o valor, podem ser identificados na estrutura conceitual da contabilidade. $\mathrm{O}$ fato jurídico pode surgir como momento de um processo, ou seja, do elo de encadeamento dos atos humanos. O fato contábil compreende, basicamente, os eventos de natureza econômica, em sua maioria, e que provocam alterações no patrimônio da entidade.

A norma jurídica pode ser considerada a forma usada para expressar o que deve ou não deve ser feito para a realização de um valor ou impedir a ocorrência de um desvalor. A norma contábil pode ser considerada uma regra complementar, obediente aos princípios fundamentais, e concebida como necessário padrão de conduta para o registro de fatos e elaboração de demonstrações e informações contábeis.

O valor pode ser definido como elemento de mediação dialética entre fato e norma, representando a expressão de um desenvolvimento histórico no plano das estimativas, no qual o homem é considerado o valor-fonte de todos os valores, pois somente ele é originariamente um ente capaz de tomar consciência do que considera importante para sua vida.

Assim, a norma, na qualidade de realidade cultural, compõe-se de conflitos e de interesses, que se renovam constantemente em decorrência das tensões que envolvem fatos e valores (relação fático-axiológica). De acordo com esse entendimento, o processo de emissão de normas, no campo contábil, pode ser formado pelas contínuas intenções de valor que, ao incidirem sobre um determinado evento econômico, definem os padrões a serem seguidos. Os padrões seriam representados pelas normas contábeis, com a inferência dos entes reguladores como expressão de poder. Notamos, então, que a norma contábil não pode surgir espontaneamente dos fatos e dos valores, pois ela não pode prescindir da apreciação da autoridade, ou seja, de quem define a oportunidade e conveniência da norma a ser consagrada. 


\section{Abordagem de Habermas segundo Laughlin}

A abordagem de Habermas, ${ }^{4}$ interpretada por Laughlin (2007), é semelhante à teoria desenvolvida por Reale. Pelo menos, quanto ao fato da regulação ser uma construção social permeada por valores e formalizada por instituições dotadas de poder normativo que interpretam os valores em consonância aos mecanismos norteadores (direções normativas). A figura 2 facilita esse entendimento.

$$
\text { Figura } 2
$$

Processo normativo segundo Habermas/Laughlin

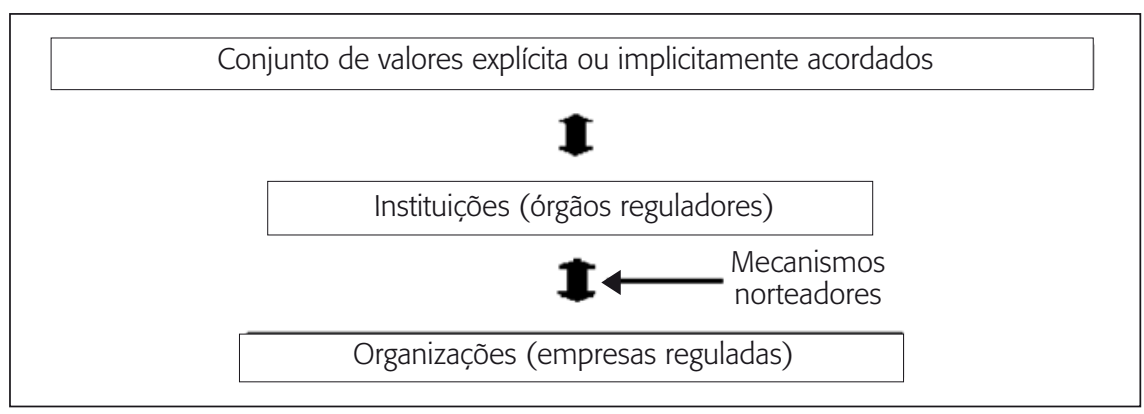

Fonte: Adaptado de Laughlin (2007:276).

Em Tenório (2007), percebe-se que o acordo (explícito ou implícito) quanto ao conjunto de valores ocorre, segundo Habermas, na "esfera pública" e que isso é determinante para a constituição da democracia. ${ }^{5}$ Para Laughlin (2007) e Broadbent (1998), os mecanismos norteadores apresentados na teoria habermasiana correspondem à lógica contábil das partidas dobradas, se-

\footnotetext{
${ }^{4}$ Jürgen Habermas nasceu em Düsseldorf (Alemanha), em 18 de junho de 1929, é filósofo e sociólogo, um dos principais autores da segunda geração do Instituto de Pesquisa Social (Escola de Frankfurt), escreveu diversas obras sobre filosofia e sociologia, seus trabalhos mais conhecidos são os relacionados à "esfera pública", à "razão comunicativa" e à "ação comunicativa".

${ }^{5}$ Tenório (2007:55) ensina: "Segundo Habermas 'a esfera pública pode ser descrita como uma rede adequada para a comunicação de conteúdos, tomada de posição e opiniões; nela os fluxos comunicacionais são filtrados e sintetizados a ponto de se condensarem as opiniões públicas enfeixadas em temas específicos' (1997:92, vol. II,)". Mais adiante, Tenório (2007: 60-61), ao explicar os conceitos de cidadania deliberativa, liberalismo e republicanismo, complementa: “(...) Para a política, no sentido de uma prática de autolegislação cívica, o paradigma não é o mercado, mas sim o diálogo. Esta concepção dialógica pensa a política como uma discussão sobre questões de valor, e não simplesmente sobre questões de preferência' (Habermas, 2004: 201)".
} 
gundo a qual os agentes, não só os contabilistas, mas todos os agentes da sociedade avaliam os custos e os benefícios de suas ações, isto é, a relação custo versus benefício é acessada pelo binômio aplicação e origem (débito e crédito), que demonstra os dois lados de uma mesma transação, ou seja, que caixa é trocado por alguma coisa.

Laughlin (2007) distingue a regulação da contabilidade da regulação contábil. ${ }^{6}$ A regulação da contabilidade é externa à contabilidade, e pode ser formalizada pelos padrões contábeis e pela regulação social baseada na lógica contábil. Portanto, é aquela emanada por uma instituição dotada de poder normativo (por exemplo, a CVM, o Conselho Federal de Contabilidade - CFC, o CPC, o Iasb, o Financial Accounting Standards Board - Fasb, o Bacen, a Superintendência de Seguros Privados - Susep, a Agência Nacional de Saúde Suplementar - ANS, a Agência Nacional de Energia Elétrica - Aneel, entre outros). ${ }^{7}$

Além dos padrões contábeis, a regulação da contabilidade é materializada, ainda, pela regulação social, isto é, a regulação econômica ou não contábil (Cardoso, 2005,e 2007; Rodrigues, 2008). Os exemplos da regulação social são vários: a Lei de Falências (tanto a antiga - Decreto-Lei $\mathrm{n}^{\circ}$ 7.661/45, quanto a atual — Lei oํ 11.101/05), a regulação tarifária (exercida, por exemplo, pela ANS, Aneel e pela Agência Nacional de Telecomunicações - Anatel), a regulação de defesa da concorrência (exercida pelo Conselho Administrativo de Defesa Econômica - Cade e pela Superintendência de Desenvolvimento Econômico - SDE), a regulação tributária. Afinal, todas essas formas de regulação se utilizam dos números providos pela contabilidade e se baseiam na lógica contábil.

Por outro lado, a regulação contábil é interna à contabilidade, isto é, surge como reação dos contabilistas e das firmas à regulação. É o que Benham (2005) chama de respostas à regulação, que podem ser lícitas ou ilícitas.

A discussão sobre respostas lícitas ou ilícitas à regulação da contabilidade pressupõe a definição de fraude, o que não é pacífico na literatura

\footnotetext{
${ }^{6}$ A regulação da contabilidade é apresentada por Laughlin (2007:277-281) como "accounting regulation", e a regulação contábil como "regulation of accounting" (Laughlin, 2007:281-285). A aparente inversão na tradução se deve ao entendimento de que a tradução literal atrapalharia a compreensão de que a primeira é externa (imposta por um ente dotado de poder normativo, como o Iasb e o CPC) e a segunda é interna (resposta à regulação).

${ }^{7}$ O Bacen, a Susep, a ANS e a Aneel estabelecem regras contábeis, inclusive planos de contas padrão, a serem observadas pelas empresas reguladas, respectivamente: instituições financeiras, entidades seguradoras, operadoras de planos de assistência à saúde e concessionárias de serviços públicos de energia elétrica.
} 
contábil. Na literatura de manipulação da informação contábil, a distinção entre earnings management e accounting fraud é baseada no compliance aos padrões contábeis, se de acordo com os princípios contábeis generalizadamente aceitos (within Gaap) seria gerenciamento, caso contrário fraude (Dechow e Skinner, 2000). Na literatura de fraude não se faz qualquer menção aos princípios contábeis, a rigor, a Associação de Examinadores de Fraude Certificados dos Estados Unidos (National Association of Certified Fraud Examiners) citados por McKee (2005:9) define fraude como "a distorção ou omissão intencional e deliberada de fatos materiais ou informações contábeis que, quando considerados em conjunto com todas as informações disponibilizadas, podem levar o leitor a alterar seu julgamento ou decisão". Esse entendimento é corroborado por Moura (2007) ao analisar o convencimento do Judiciário brasileiro quanto à ocorrência de fraudes contábeis em três casos de crimes falimentares. ${ }^{8}$

Laughlin (2007:282-285) argumenta que a resposta ou reação à regulação pressupõe a classificação dos valores e das atividades das firmas em núcleo central (sacred) e periféricos (secular), de forma que a empresa estaria disposta a sacrificar os valores e as atividades periféricas para preservar seus valores sagrados. De forma bastante intuitiva, percebemos que todos nós tendemos a agir dessa maneira quando nos vemos ameaçados. Por exemplo, quando tropeçamos e caímos, nossa primeira reação é projetar os braços à frente para proteger o rosto (centro), mesmo que em detrimento das mãos (periférico).

Feita essa distinção de valores e atividades, a análise das reações à regulação passa para a questão da absorção, pois quatro situações são possíveis, duas de primeira ordem (que o núcleo central não é afetado) e duas de segunda ordem (que o núcleo central é afetado). Para evitar que o núcleo seja afetado (primeira ordem), a organização pode agir proativamente (evitando que a organização seja afetada pela regulação) ou reativamente (quando a organização é afetada, mas consegue se reorientar de forma a proteger o núcleo). Por outro lado, quando o núcleo é afetado, a organização também pode optar por se alterar (evolução), ou pode ser forçada a se alterar (colonização).

A seção seguinte é dedicada à análise da Lei no 11.638/07 e da MP no 449/08 à luz dessas teorias.

\footnotetext{
${ }^{8}$ Embora o tema fraude contábil não seja o foco deste artigo, registra-se que não concordamos com a abordagem de Dechow e Skinner (2000), pois significaria a primazia da forma (Gaap) sobre a essência econômica, contrariando a estrutura conceitual básica da contabilidade, conforme referendado pela CVM mediante a Deliberação no 539/08.
} 


\section{A Lei no $11.638 / 07$ e a MP no $449 / 08$}

A Lei no 11.638, sancionada em 28 de dezembro de 2007, é fruto de mais de uma década de debates na academia, na CVM, no CFC, no Ministério da Fazenda e no Congresso Nacional. A MP no 449/08, editada em 3 de dezembro de 2008, tem o propósito de "corrigir" alguns aspectos não adequadamente

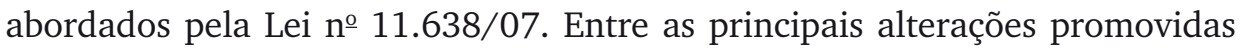
por essas normas na contabilidade societária das companhias abertas brasileiras estão:

v obrigatoriedade de elaboração, auditoria e divulgação da demonstração dos fluxos de caixa (DFC) e a desobrigação de se elaborar a demonstração das origens e aplicações de recursos (Doar);

v obrigatoriedade de elaboração, auditoria e divulgação da demonstração do valor adicionado (DVA);

v criação do subgrupo intangível no ativo não circulante;

v extinção da conta lucros acumulados do patrimônio líquido;

v proibição de se reconhecer novas reavaliações;

v exigência de se marcar a mercado os títulos e valores mobiliários destinados à negociação imediata ou disponíveis para venda;

- exigência de se ajustar a valor presente os recebíveis e os exigíveis a longo prazo, sendo facultado o mesmo tratamento para os títulos a receber, classificados no ativo circulante, e para os títulos a pagar classificados no passivo circulante;

v exigência de se reconhecer perdas por irrecuperabilidade do valor contábil (impairment);

v alteração da definição de ativo, de forma a atualizar a lei conforme framework for the preparation and presentation of financial statements elaborado pelo Iasb, cujo foco deixa de ser a propriedade e passa a ser o trinômio "benefício, risco e controle"; consequentemente, há de forma implícita a exigência de se reconhecer o imobilizado e o respectivo passivo assumido em decorrência de arrendamento financeiro;

v aprimora o conteúdo informacional das notas explicativas;

- elimina a conta diferido e o somatório ativo permanente, ambos do ativo não circulante, da mesma forma que elimina a conta resultado de exercícios 
futuros e o somatório exigível a longo prazo, ambos do passivo não circulante;

v alterou, na demonstração do resultado do exercício, a rubrica "resultado não operacional" por "outras receitas e outras despesas";

v alterou a definição de coligada, para os fins da adoção do método da equivalência patrimonial.

Além disso, a Lei no 11.638/07 e a MP oㅡ 449/08 preveem:

v a obrigatoriedade da CVM emitir normas contábeis em consonância aos padrões internacionais de contabilidade;

v a obrigatoriedade das empresas de grande porte ${ }^{9}$ adotarem os padrões contábeis dispostos na Lei oㅡ 11.638/07 e de submeterem suas demonstrações contábeis à análise de auditores externos (independentes) registrados na CVM;

- desvinculação da contabilidade societária em relação à apuração da base de cálculo do imposto de renda, estabelecendo "neutralidade tributária" aos ajustes decorrentes da adoção dos IFRS pelas empresas brasileiras que optarem pelo regime tributação de transição (RTT).

Aplicando-se as teorias da regulação apresentadas na seção anterior às alterações promovidas pela Lei ํㅜ 11.638 /07 e pela MP no 449/08 na LSA, tem-se que as teorias, embora concorrentes, podem ser aplicadas de forma complementar e que em alguns casos uma teoria parece ser mais adequada que em outros.

A substituição da Doar pela DFC e a obrigatoriedade da DVA podem ser explicadas pela teoria do interesse público, afinal, quantidade razoável de companhias abertas divulgou essas informações de forma complementar, em notas explicativas às demonstrações contábeis de 2007 e/ou em seu website. ${ }^{10}$ Pode-se supor que essa medida veio atender aos anseios dos usuários das informações contábeis, pois agora todas as companhias abertas deverão

\footnotetext{
${ }^{9}$ Empresas de grande porte são, pela legislação em vigor (parágrafo único do art. $3^{\circ}$ da Lei ํo $11.638 / 07$ ), as que possuem ativo total superior a $\mathrm{R} \$ 240$ milhões ou receita bruta anual superior a R\$ 300 milhões.

${ }^{10}$ Das 499 companhias abertas cujas demonstrações financeiras padronizadas (DFP) relativas a 2007 estavam disponíveis no site da Bovespa (www.bovespa.com.br), em 2 de abril de 2008, $41,3 \%$ divulgaram a DFC e $18,4 \%$ divulgaram a DVA.
} 
evidenciar a DFC e a DVA, e antes da Lei $n^{-}$11.638/07 isso era facultativo. ${ }^{11}$ Entretanto, essa suposição fica prejudicada quando se excluem da amostra as empresas certificadas pela Bovespa quanto à adoção de práticas de governança corporativa (níveis 1, 2, Novo Mercado e Bovespa Mais - que se comprometem a evidenciar a DFC), restando 345 empresas, das quais 16,8\% e 9,9\% evidenciaram, respectivamente, a DFC e a DVA como informações adicionais às notas explicativas. Essa medida legal atende, ainda, às demandas das companhias abertas, que antes incorriam nos custos de elaboração, auditoria e publicação da Doar, mesmo que o senso comum sugerisse que poucos leitores das demonstrações contábeis atribuíam algum valor a ela.

A proibição de se reconhecer novas reavaliações também pode ser vista como uma regulação que visa atender à demanda do interesse público porque, segundo o senso comum, muitas empresas se utilizavam da reavaliação dos itens tangíveis do imobilizado para manipularem os números contábeis.

Segundo Iudícibus, Martins e Gelbcke (2007:345),

é sabido o fato de que muitas empresas têm feito uso de reavaliações para reduzir, deliberadamente, distribuição de dividendos, mesmo quando de imobilizados que não serão repostos. Outras empresas têm adotado a reavaliação quando sentem que seu patrimônio líquido está baixo e os índices de debt equity são comprometedores (...).

Dessa forma, poder-se-ia argumentar que a proibição de se reconhecer novas reavaliações tem por propósito evitar que as companhias abertas distorçam as informações prestadas ao mercado, primando, assim, pela confiabilidade da informação. É curioso ressaltar que as normas internacionais de contabilidade permitem a reavaliação do imobilizado (§§ 31 a 42 do IAS 16), portanto, nesse ponto, a Lei no $11.638 / 07$ não permitirá a adoção da faculdade prevista nos padrões emitidos pelo Iasb.

A exigência de marcação a mercado para os títulos financeiros destinados à negociação imediata ou disponíveis para venda, assim como o ajuste a valor presente de realizáveis e exigíveis a longo prazo, pode ser entendida tanto pela teoria tridimensional, quanto pela abordagem de Habermas interpretada por Laughlin. Pode-se argumentar que o valor compartilhado pela

\footnotetext{
${ }^{11}$ As empresas certificadas pela Bovespa quanto às práticas de governança corporativa (Novo Mercado, Bovespa Mais, Nível 2 e Nível 1) eram obrigadas a divulgar a DFC, em conjunto com as notas explicativas.
} 
sociedade não é mais a informação baseada no custo histórico (registro pelo valor original ou custo como base de valor), mas a mensuração pelo fair value. ${ }^{12}$ Afinal, segundo Reale, as normas precisam acompanhar as alterações e as novas demandas sociais (valores). Nesse sentido, é interessante observar que em função da recente crise financeira o critério de mensuração de ativos pelo fair value foi criticado por acadêmicos, reguladores, investidores e intermediários da informação contábil como uma das causas da crise. Consequentemente, o "pacote econômico" proposto pelo presidente George W. Bush ao Congresso estadunidense contemplava, além de bilhões de dólares para sanear instituições financeiras, a proposta de se flexibilizar a adoção da marcação a mercado para títulos e valores mobiliários. No Brasil, tal flexibilização também foi debatida (informalmente), mas a CVM a rejeitou. ${ }^{13}$

A criação do subgrupo intangível no ativo não circulante, a extinção da conta lucros acumulados do patrimônio líquido apurado no final do exercício, a exigência de se reconhecer o impairment e a exigência de se reconhecer adequadamente o ativo adquirido e o passivo assumido mediante operações de arrendamento mercantil financeiro (capital lease) são todas alterações da LSA, já previstas em normas infralegais emitidas pelos diversos órgãos reguladores da informação contábil.

A Deliberação CVM no 488/05, cujo objetivo foi a redução das diferenças entre os padrões contábeis brasileiros e os internacionais, tornou obrigatória a evidenciação do ativo não circulante classificado em investimentos, imobilizado, intangível e diferido e, ainda, exigiu a evidenciação do somatório do realizável a longo prazo com o ativo permanente como ativo não circulante. Portanto, a Lei no 11.638/07 só recepcionou em parte a Deliberação CVM nº 488/05, como forma de atender ao suposto interesse público da convergência dos padrões nacionais de contabilidade aos internacionais.

A extinção da conta lucros acumulados só reitera e "força" a observância do disposto no § 6o do art. 202 da LSA (cuja redação foi acrescida pela Lei no 10.303/01), que exigiu a destinação integral do lucro líquido a cada período, quer mediante a distribuição de dividendos ou na forma de constituição das

\footnotetext{
${ }^{12}$ Sunder (2008) apresenta crítica ao uso do termo "valor justo", por ser uma forma do regulador evitar discussões em relação à norma. Afinal, quem criticar o uso do "valor justo" pela contabilidade poderia ser taxado como um defensor do "valor injusto".

${ }^{13} \mathrm{O}$ professor Eliseu Martins, no dia 11 de novembro de 2008, durante discurso de posse no cargo de diretor da Comissão de Valores Mobiliários comentou que, no que tange à informação contábil, a crise não foi motivada pela norma de marcação a mercado, mas por seu mau uso, portanto, não haveria necessidade de se alterar a norma.
} 
reservas de lucros. O valor objetivado pelo legislador de 2001, aparentemente, foi a proteção do acionista minoritário e a busca de maior previsibilidade dos fluxos de caixa a serem distribuídos na forma de dividendos - supostamente, em defesa do interesse público.

A obrigatoriedade de reconhecimento periódico do teste de recuperabilidade do valor contábil dos ativos (impairment) já estava prevista no Pronunciamento CPC no 1 , de 14 de setembro de 2007, que até a emissão da Lei no 11.638/07 ainda era carente de convalidação por parte da CVM e do CFC. Além de buscar a redução das diferenças entre os padrões contábeis brasileiros e os internacionais, o valor objetivado pelo Pronunciamento CPC no 1 é a confiabilidade da informação contábil, cuja prudência é uma de suas características qualitativas secundárias.

A necessidade de se reconhecer adequadamente as operações de arrendamento mercantil financeiro (capital lease) já era prevista na Resolução CFC no 921/01. Entretanto, essa resolução não vinha sendo observada pelas empresas brasileiras por conta da legislação do imposto de renda (que permite/ permitia a dedutibilidade integral do valor pago ou devido a título de contraprestação de arrendamento mercantil), e de regulações setoriais - principalmente a regulação exercida pelo Bacen. $\mathrm{O}$ valor objetivado pelo $\mathrm{CFC}$ ao emitir a Resolução no 921 foi a primazia da essência sobre a forma, uma das características qualitativas secundárias da confiabilidade da informação contábil.

A obrigatoriedade da CVM emitir normas contábeis em consonância aos IFRS pode ser entendida como fruto da teoria da competição entre os grupos de interesse. De um lado (grupo 1) estão os investidores estrangeiros e grandes investidores brasileiros (que pretendem reduzir seus custos de transação para identificar os riscos e comparar as empresas brasileiras com as estrangeiras), as empresas brasileiras que captam recursos no exterior e/ou cuja holding é estrangeira e, ainda, que controlam empresas em outros países e precisam consolidar todo o grupo econômico (que pretendem gerar um único conjunto de demonstrações contábeis que atenda simultaneamente investidores estrangeiros e brasileiros), e as grandes empresas de auditoria (que pretendem reduzir os custos de treinamento de pessoal). De outro lado (grupo 2) estão as companhias abertas que não lançaram depositary receipts e cuja holding é brasileira (que estão satisfeitas com os padrões contábeis brasileiros e não gostariam de alterar os padrões contábeis, uma vez que isso lhes imputaria mais custos imediatamente sem qualquer benefício no curto prazo) e as pequenas e médias empresas de auditoria (que provavelmente não estão preparadas para treinarem seus profissionais nos padrões internacionais de contabilidade e temem maior concentração de mercado por parte das firmas internacionais de 
auditoria que poderá ser provocada em função do intercâmbio de profissionais de auditoria entre as diversas "filiais" das firmas de grande porte). Nesse cenário, é razoável supor que o grupo 1 tenha capacidade de exercer maior pressão sobre o regulador (CVM, Presidência da República e Congresso Nacional) que o grupo 2. Afinal, o grupo 2 é mais disperso que o grupo 1, e mais suscetível ao efeito free-rider, e o grupo 1 tem mais reservas, de forma que o custo da pressão exercida lhe é menos caro do que para o grupo 2 .

O aprimoramento do conteúdo informacional das notas explicativas, as demais alterações na estrutura das demonstrações contábeis (eliminação das contas e somatórios: diferido, ativo permanente, resultado de exercícios futuros, exigível a longo prazo; alteração de resultado não operacional por outras receitas e outras despesas), assim como a alteração da definição de coligada (o critério deixa de ser a participação "formal" de no mínimo 10\% sobre o capital social, para ser o efetivo exercício de influência na definição das políticas operacional e financeira da entidade investida) são consequências do processo de adoção dos IFRS no Brasil.

Em debates sobre propostas de alteração da LSA, no Congresso Nacional, empresas e Poder Executivo acordaram que os ajustes contábeis necessários à adoção dos IFRS não teria qualquer impacto tributário (nem pró-empresas, nem pró-fisco). Nesse espírito, a redação original do art. 177 da LSA, que previa a não interferência tributária na apuração do resultado contábil e que não foi respeitado pelo fisco ao longo de três décadas de vigência da LSA, foi alterada com o propósito de se fazer valer a não interferência tributária idealizada por Mário Henrique Simonsen, desde 1976. ${ }^{14}$

Não obstante as negociações prévias e a nova redação do art. 177 (dada pela Lei ํㅜ 11.638/07), o fisco, temendo redução de arrecadação, não emitiu instrução normativa que regulamentasse a nova sistemática de

\footnotetext{
${ }^{14}$ Pela redação original do art. 177, as empresas, ao elaborar suas demonstrações contábeis, deveriam seguir estritamente os padrões contábeis (contabilidade societária), uma vez que os ajustes necessários à apuração da base de cálculo do imposto de renda (IR) seriam efetuados em relatório à parte, o livro de apuração do lucro real (Lalur). O fisco exigia que para a despesa ser aceita como dedutível da base de cálculo do IR, deveria ser reconhecida pela contabilidade societária — o que tornou inócuo o fim objetivado por Simonsen. A alteração promovida pela Lei no 11.638/07 nesse artigo invertia a lógica proposta por Simonsen. Uma vez que o fisco não abriu mão de interferir na contabilidade societária, a nova sistemática previa que as empresas, ao elaborarem as demonstrações contábeis obrigatórias, deveriam atender primeiro às exigências do fisco e, após apurar o IR devido, fariam ajustes para observar os padrões contábeis. O relatório para se realizar esses ajustes foi apelidado de livro de apuração do lucro contábil (Laluc) — o que corresponde a uma resposta das empresas à postura adotada pelo fisco ao longo de três décadas.
} 
apuração da base de cálculo do IR. Por outro lado, as empresas, temendo aumento da carga tributária, ameaçaram não adotar os IFRS - uma afronta aos ditames da "nova" LSA.

Foi nesse contexto de insegurança jurídica que, um ano depois da publicação da Lei nº 11.638/07, a Presidência da República emitiu a MP no 449/08 que, entre outras coisas, estabeleceu o RTT e definiu "neutralidade tributária" aos ajustes decorrentes da adoção dos IFRS pelas empresas brasileiras. ${ }^{15}$

Fora a questão dos efeitos tributários da Lei no 11.638/07, o debate sobre a obrigatoriedade de publicação/divulgação das demonstrações contábeis, por parte das empresas de grande porte, recebeu significativa atenção na mídia especializada. Como exemplo, tem-se a reportagem publicada na revista Carta Capital de fevereiro de 2008, na qual foram apresentados argumentos contraditórios sobre o mesmo ponto:

No TozziniFreire Advogados, a avaliação é de que as limitadas de grande porte estão, sim, livres do ônus da divulgação. (...) No Barbosa, Müssnich \& Aragão, chegou-se à mesma conclusão: "A obrigatoriedade é apenas a de escriturar e elaborar as demonstrações conforme a Lei das Sociedades Anônimas".

Modesto Carvalhosa interpreta que a lei estende a obrigatoriedade da publicação às limitadas. "É uma questão de lógica jurídica e interpretação sistemática da lei", justifica. Segundo ele, não faz sentido o diploma legal exigir a escrituração e a elaboração dos balanços, além da certificação por auditores independentes, se tais informações não chegarem ao público.

O argumento de Modesto Carvalhosa parece ser bastante lógico, mas é parcial, pois desconsidera que muitas das empresas de grande porte já são auditadas por auditores independentes (eventualmente, até registrados na CVM), por demanda dos sócios/acionistas controladores — seja

\footnotetext{
${ }^{15}$ O RTT é um regime ao qual as empresas contribuintes do IR pelo lucro real ou pelo lucro presumido poderão optar caso queiram gozar da neutralidade tributária na convergência aos padrões internacionais. Entende-se por neutralidade tributária o fato de as receitas e despesas reconhecidas na contabilidade societária por conta da adoção das práticas contábeis "inovadas" pela Lei n⿳0 11.638/07 e pela própria MP no 449/08, seguindo de forma plena os IFRS, não serem tributáveis nem dedutíveis da base de cálculo do IR. Tal regime é chamado de transitório (segundo "T" de RTT) pelo fato da MP no 449/08 ter "estabelecido a obrigação" do Congresso Nacional alterar definitivamente a legislação tributária em sintonia ao "princípio da neutralidade tributária" até 2010. Mas, como gatilho, estabelece que o RTT vigorará até que a legislação tributária seja alterada nesse sentido, mesmo que o referido prazo não seja observado pelo Congresso. Ressalte-se que o RTT não se restringe ao IR, também abrange as contribuições CSLL, PIS/Pasep e Cofins.
} 
pelo fato de o controlador estar distante da empresa (como é o caso da holding estrangeira) ou pelo fato de o controle ser compartilhado entre dois ou mais sócios/acionistas —, ou em função de a holding brasileira ser companhia aberta e precisar consolidar as demonstrações contábeis das diversas empresas do grupo.

Mesmo assim, poder-se-ia evocar a teoria da competição entre grupos de interesse para compreender a obrigatoriedade da auditoria, independentemente mesmo sem a publicação/divulgação das demonstrações contábeis. Para se analisar essa questão é necessário verificar os documentos que antecederam a Lei $n^{\circ}$ 11.638/07. Pelo anteprojeto de reformulação da Lei $n^{0}$ 6.404/76 e pelo Projeto de Lei oㅜ 3.741/00 as empresas de grande porte seriam obrigadas a publicar e arquivar no Registro do Comércio suas demonstrações contábeis. Posteriormente, o substitutivo do projeto de lei previa que as empresas de grande porte deveriam divulgar suas demonstrações contábeis pela internet, como se o "interesse público" demandasse a redução de assimetria informacional entre as companhias abertas (que divulgam suas demonstrações contábeis) e suas concorrentes constituídas sob a forma de sociedades por cotas de responsabilidade limitada (Ltda.) ou sociedades por ações de capital fechado (companhias fechadas), que não divulgam. Só que muitas das empresas de grande porte que hoje são Ltda. ou companhias fechadas já foram companhias abertas que fecharam seu capital objetivando reduzir os custos de transação (compliance às regras da CVM) e para deixarem de divulgar seu desempenho e sua situação econômico-financeira ao mercado, mesmo com o ônus de pararem de captar recursos no mercado de ações. Portanto, exigirlhes a publicação de suas demonstrações contábeis lhes seria prejudicial, uma vez que lhes imputaria custos expressivos e tornaria inócua a reestruturação societária que realizaram no passado.

Então, é razoável supor que essas empresas exerceram pressão sobre o Legislativo, no sentido de evitar a obrigatoriedade da publicação - seguindo a estrutura teórica proposta por Laughlin (2007), poder-se-ia dizer que as empresas de grande porte foram proativas no sentido de evitar serem afetadas pela regulação, afinal, a palavra publicação foi substituída por divulgação. A diferença prática entre publicação e divulgação é bastante significativa e impacta diretamente o fluxo de caixa dessas entidades. A publicação pressupõe que as demonstrações contábeis sejam impressas em jornais de grande circulação e em diário oficial, ao passo que a divulgação pode ser em qualquer outra mídia, até mesmo no site da própria empresa. Sem a publicação, os jornais que imaginaram multiplicar suas receitas no primeiro trimestre de cada ano (período no qual as empresas publicariam suas demonstrações contábeis nor- 
malmente apuradas em 31 de dezembro) não teriam mais essa significativa receita (externalidade positiva). Por isso, é razoável supor que tenham exercido pressão sobre o Legislativo, no sentido de tornar a publicação (em jornal) obrigatória sim.

Considerando as pressões em sentidos opostos e, razoavelmente, de mesma intensidade, é factível compreender o porquê do texto final da Lei no 11.638/07 não ter estabelecido a obrigatoriedade nem de publicação nem de divulgação das demonstrações contábeis por parte das empresas de grande porte, mantendo-se o status quo (assimetria informacional entre companhias abertas e seus concorrentes de capital fechado e limitadas). Mas se fosse do "interesse público" a evidenciação de como as empresas de grande porte consomem os recursos disponibilizados pela sociedade, isso não foi nem seria atendido. Afinal, tal informação só chegaria à sociedade se fosse obrigatória a publicação/divulgação do balanço social - o que não foi contemplado em qualquer dos documentos oficiais que precederam a Lei no 11.638/07. Essa questão não foi resolvida com a edição da MP no 449/08.

\section{Considerações finais}

Entendendo-se a contabilidade como uma instituição social, cujo fim compreende a redução da assimetria informacional, o delineamento de incentivos e a estruturação e sinalização de mecanismos de avaliação de desempenho, foram analisadas cinco teorias da regulação: (i) do interesse público, segundo a qual a regulação busca corrigir falhas de mercado e zelar pelo interesse público; (ii) da captura, segundo a qual a regulação gera lucros anormais positivos para as empresas reguladas; (iii) da competição entre grupos de interesse, segundo a qual a regulação é desenhada conforme os interesses do grupo que exercer maior pressão relativa sobre o regulador; (iv) tridimensional do direito; e (v) a abordagem de Habermas, segundo as quais a regulação é uma construção social, portanto, permeada de valores e estabelecida por uma instituição dotada de poder. Essas duas últimas teorias (realiana e habermasiana) são vinculadas à democratização do processo contábil na medida em que os diferentes atores da sociedade, além dos responsáveis pelo registro e normatização, estão presentes nessas perspectivas (ou, pelo menos, seus valores). Ou seja, a contabilidade deixa de ser apenas um meio, uma ferramenta, um instrumento, um mecanismo, para aproximar-se da modernidade, para contribuir à emancipação do homem. De meio indo em direção ao fim, abrindo 
a "caixa-preta" de um processo de registro que muitas vezes, senão sempre, escapam dos olhares do demos. ${ }^{16}$

Distinguiu-se regulação da contabilidade e regulação contábil. Conforme Laughlin (2007), a primeira é externa à contabilidade e estabelecida por um ente dotado de poder, é a regulação propriamente dita. Por sua vez, a regulação contábil foi apresentada como a resposta contábil à regulação. Portanto, este artigo tratou da regulação da contabilidade.

Finalmente, demonstraram-se como aquelas cinco teorias poderiam ser utilizadas para se compreender algumas das principais alterações na política contábil estabelecidas pela Lei no 11.638/07 e pela MP no 449/08, tendo-se percebido que ora uma teoria é mais adequada à explicação de determinada alteração, ora outra teoria. Percebeu-se, ainda, que as teorias realiana e habermasiana, por contemplarem os valores sociais que nortearam a regulamentação, são adequadas para se interpretar (ex post) a regulação.

Pesquisas futuras poderão testar empiricamente os argumentos aqui apresentados. Sugere-se, também, que se busque identificar quais grupos de interesse prevaleceram e conseguiram obter a emissão de pronunciamentos pelo CPC aderentes aos seus incentivos.

\section{Referências}

ANTHONY, Robert N.; REECE, James S. Accounting principles. 6. ed. Illinois: Irwin, 1989.

BALDWIN, Robert; CAVE, Martin. Understanding regulation. Theory, strategy, and practice. Oxford: Oxford University Press, 1999.

BEAVER, William H. Financial reporting: an accounting revolution. 3. ed. New Jersey: Prentice Hall, 1998.

BECKER, Gary S. A theory of competition among pressure groups for political influence. Quarterly Journal of Economics, n. 98, p. 371-400, Aug. 1983.

BENHAM, Lee. Licit and illicit firm responses to public regulation. In: MENARD, C.; SHIRLEY, M. M. (Orgs.). Handbook of new institutional economics. New York: Kluwer Press, 2005.

BERNSTEIN, Marver H. Regulating business by independent commission. New York, 1955.

${ }^{16}$ Demos, em grego, significa povo. 
BRAGA, Hugo R.; ALMEIDA, Marcelo C. Mudanças contábeis na Lei Societária: Lei no 11.638, de 28-12-2007. São Paulo: Atlas, 2008.

BRASIL. Comissão de Valores Mobiliários. Anteprojeto de reformulação da Lei $n$. 6.404/76. Disponível em: <www.cvm.gov.br>. Acesso em: 21 jan. 2008.

. Comissão de Valores Mobiliários. Comunicado ao mercado, de 14/01/2008. Disponível em: <www.cvm.gov.br>. Acesso em: 21 jan. de 2008.

. Comissão de Valores Mobiliários. Deliberação n. 29, de 5 de fevereiro de 1986. Aprova e referenda o pronunciamento do Ibracon sobre a estrutura conceitual básica da contabilidade. DOU, DF, 13 fev. 1986.

. Comissão de Valores Mobiliários. Deliberação n. 539, de 14 de março de 2008. Aprova o pronunciamento conceitual básico do CPC que dispõe sobre a estrutura conceitual para a elaboração e apresentação das demonstrações contábeis. DOU, DF, 14 mar. 2008.

. Comissão de Valores Mobiliários. Projeto de Lei n. 3.741/00. Disponível em: www.cvm.gov.br. Acesso em: 21 de janeiro de 2008.

. Comissão de Valores Mobiliários. Projeto de lei n. 3.741/00 — substitutivo. Disponível em: <www.cvm.gov.br>. Acesso em: 21 jan. 2008.

. Congresso Nacional. Lei n. 11.101/2005. Regula a recuperação judicial, a extrajudicial e a falência do empresário e da sociedade empresária. $D O U$, edição extra, DF, 9 fev. 2005.

. Presidência da República. Decreto-Lei n. 7.661/45. Lei de Falências. DOU, DF, 31 jul. 1945.

. Congresso Nacional. Lei n. 6.404/76. Dispõe sobre as Sociedades por Ações. DOU, Poder Executivo, Brasília, DF, 17 dez. 1976. Suplemento.

. Congresso Nacional. Lei n. 11.638/08. Altera e revoga dispositivos da Lei n. 6.404, de 15 de dezembro de 1976, e da Lei n. 6.385, de 7 de dezembro de 1976, e estende às sociedades de grande porte disposições relativas à elaboração e divulgação de demonstrações financeiras. $D O U$, edição extra, Poder Executivo, Brasília, DF, 28 dez. 2007.

. Presidência da República. Medida Provisória n. 449, de 3 de dezembro de 2008. Altera a legislação tributária federal relativa ao parcelamento ordinário de débitos tributários, concede remissão nos casos em que especifica, institui regime tributário de transição e dá outras providências. DOU, Poder Executivo, Brasília, DF, 4 dez. 2008. 
BROADBENT, J. The gendered nature of 'accounting logic': pointers to an accounting that encompasses multiple values. Critical Perspectives on Accounting, v. 9, n. 3, p. 267-297, 1998.

CARDOSO, Ricardo Lopes. Regulação econômica e escolhas de práticas contábeis: evidências no mercado de saúde suplementar brasileiro. 2005. Tese (Doutorado em Ciências Contábeis) — Departamento de Contabilidade e Atuária, Universidade de São Paulo, São Paulo.

- Reflexos da regulação econômica na informação contábil prestada pelo ente regulado. In: PECI, A. (Org.). Regulação no Brasil. São Paulo: Atlas, 2007. p. 147-178.

DECHOW, Patricia M.; SKINNER, Douglas J. Earnings management: reconciling the views of accounting academics, practitioners, and regulators. Accounting Horizons, v. 14, n. 2, 2000.

ERNST \& YOUNG; FIPECAFI. Manual de normas internacionais de contabilidade: IFRS versus normas brasileiras. São Paulo: Atlas, 2009.

IUDÍCIBUS, Sérgio; MARTINS, Eliseu; GELBCKE, Ernesto R. Manual de contabilidade das sociedades por ações (aplicável às demais sociedades). 7. ed. São Paulo: Atlas, 2007.

; ___ . Manual de contabilidade das sociedades por ações (aplicável às demais sociedades). São Paulo: Atlas, 2008. Suplemento.

KING, Thomas A. More than a numbers game: a brief history of accounting. New Jersey: Wiley, 2006.

LAUGHLIN, Richard. Critical reflections on research approaches, accounting regulation and the regulation of accounting. The British Accounting Review, v. 39, p. 271-289, 2007.

MAUTZ, R. K. Accounting as a social science. The Accounting Review, v. 38, n. 2, p. 317-325, Apr. 1963.

McCOWEN, George B. The accountants as artist. The Accounting Review, v. 21, n. 2, p. 204-211, Apr. 1946.

McKEE, Thomas E. Earnings management: an executive perspective. Ohio: Thomson, 2005.

McLEAY, Stuart; ORDELHEIDE, Dieter; YOUNG, Steven. Constituent lobbying and its impact on the development of financial reporting regulations: evidence from Germany. In: LEUZ, C.; PFAFF, D.; HOPWOOD, A. The economics and politics of accounting. Oxford: Oxford University Press, 2004. p. 285-316. 
MOURA, Denia. Análise dos fatores de convencimento do juízo brasileiro quanto à ocorrência de fraude contábil: um estudo de caso múltiplo das Galus, da Encol e do Banco Santos. 2007. Dissertação (Mestrado em Gestão de Empresas) — Escola Brasileira de Administração Pública e de Empresas, Fundação Getulio Vargas, Rio de Janeiro.

ORDELHEIDE, Dieter. The politics of accounting: a framework. In: LEUZ, C.; PFAFF, D.; HOPWOOD, A. The economics and politics of accounting. Oxford: Oxford University, 2004. p. 269-284.

PELTZMAN, Sam. Toward a more general theory of regulation. Journal of Law and Economics, v. 19, p. 211-240, Aug. 1976.

POHLMANN, Marcelo C.; ALVES, Francisco J. S. Regulamentação. In: IUDÍCIBUS, S. D.; LOPES, A. B. (Orgs.). Teoria avançada da contabilidade. São Paulo: Atlas, 2004. p. 233-273.

POSNER, Richard A. Taxation by regulation. Bell Journal of Economics and Management Science, n. 2, p. 22-50, Spring 1971.

REALE, Miguel. Pluralismo e liberdade. São Paulo: Saraiva, 1963. . Experiência e cultura. São Paulo: Grijalbo/Edusp, 1977. . Fontes e modelos do direito. São Paulo: Saraiva, 1994. . Noções preliminares do direito. São Paulo: Saraiva, 1995. . Filosofia do direito. São Paulo: Saraiva, 1996. . Teoria tridimensional do direito. São Paulo: Saraiva, 2005.

RODRIGUES, Adriano. Gerenciamento da informação contábil e regulação: evidências no mercado brasileiro de seguros. 2008. Tese (Doutorado em Ciências Contábeis) - Departamento de Contabilidade e Atuária, Universidade de São Paulo, São Paulo.

SILVA, Marcelo A. Análise da regulação contábil: um ensaio à luz da teoria tridimensional do direito, da teoria normativa da contabilidade e do gerenciamento da informação contábil, numa perspectiva interdisciplinar. 2007. Dissertação (Mestrado em Gestão de Empresas) — Escola Brasileira de Administração Pública e de Empresas, Fundação Getulio Vargas, Rio de Janeiro.

STERLING, R. Toward a science of accounting. Financial Analysts Journal, n. 31, p. 28-36, 1975.

STIGLER, George J.; FRIEDLAND, Claire. What can regulators regulate? The case of electricity. Journal of Law and Economics, n. 5, p. 1-16, Oct. 1962. 
. The theory of economic regulation. Bell Journal of Economics and Management Science, n. 2, p. 3-21, Spring 1997.

SUNDER, Shyam. Econometrics of fair values. Accounting Horizons, v. 22, n. 1, p. 111-125, Mar. 2008.

SZUSTER, Natan et al. Contabilidade geral: introdução à contabilidade societária. 2. ed. São Paulo: Atlas, 2008.

TENÓRIO, Fernando Guilherme. Cidadania e desenvolvimento local. Rio de Janeiro: FGV; Ijuí: Unijuí, 2007.

VERRECCHIA, Robert E. Policy implications from the theory-based literature on discloure. In: LEUZ, C.; PFAFF, D.; HOPWOOD, A. The economics and politics of accounting. Oxford: Oxford University Press, 2004. p. 149-163.

VISCUSI, W. K.; VERNON, J. M.; HARRINGTON JR., J. E. Economics of regulation and antitrust. 3. ed. Cambridge: The MIT Press, 2000. 